\title{
Evaluasi Ruang Terbuka Hijau di Kecamatan Sleman Kabupaten Sleman
}

DOI 10.18196/pt.2015.048.114-121

\author{
Vinda Catur Nugroho \\ PT. Perkebunan Minanga Ogan, \\ Jl. Suryo No. 227, Kebayoran Baru, Jakarta, Daerah Khusus Ibukota Jakarta 12180, Indonesia, Telp +62 2172781275 , \\ e-mail: vindactr@yahoo.com
}

\begin{abstract}
ABSTRAK
Perkembangan daerah perkotaan sering berdampak negatif pada aspek lingkungan, seperti penurunan luas daerah yang digunakan untuk ruang terbuka hijau. Oleh karena itu, perlu untuk melaksanakan penelitian tentang evaluasi ruang terbuka hijau. Penelitian bertujuan untuk mengevaluasi ketersediaan, bentuk dan menciptakan model penataan ruang terbuka hijau. Penelitian dilakukan dengan metode survei di Kabupaten Sleman yang teknis pelaksanaan dilakukan dengan observasi, kuesioner, pengumpulan data primer dan sekunder. Pemilihan pengamatan lokasi dibuat secara purposive. Data yang telah dikumpulkan dianalisis secara deskriptif. Hasil penelitian ini menunjukkan bahwa kabupaten Sleman memiliki ruang terbuka hijau publik kurang dari 35,84 hektar atau 1,14\% dari total luas daerah 624,4 hektar, yang disebut pada UU RI No. 26 tahun 2007. Sebuah ruang terbuka model penataan hijau model referensi untuk meningkatkan nilai estetika, fungsional dan increast ruang terbuka hijau yang ada di kabupaten Sleman dapat dilakukan dengan mengembangkan taman kota, hutan kota, tanaman pinggir jalan dan air mancur yang memiliki nilai fungsional dan estetika.

Kata kunci: Evaluasi ruang terbuka hijau, Kabupaten Sleman
\end{abstract}

\begin{abstract}
The development of urban area gives negative impact on the environmental aspects, such as the decreasing of areas for green open space. Therefore, it is necessary to implement the research about evaluation of green open space. This research aims to evaluate availability, form and create green open space structuring model in the district of Sleman. The research was conducted by survey method which technical implementation was done by observation, questionnaires, and primary and secondary data collection. The choice of location observations made purposively. The data that has been collected was analyzed descriptively. The results of this research showed that the district of Sleman have public green open space which is less that 35.84 hectares or 1.14\% of the area that 624.4 hectares, was referred to UU RI No. 26 year 2007. A green open space structuring model as a reference model to increased the value of aesthetic, functional and to increast the existing green open spaces in the district of Sleman can be done with the developing of city parks, city forests, roadside plants and water fountains that have a functional and aesthetic value.

Keywords: Evaluation of green space, Sleman district
\end{abstract}

\section{PENDAHULUAN}

Kabupaten Sleman, adalah kabupaten di Provinsi Daerah Istimewa Yogyakarta, Indonesia, dengan Ibukota Kecamatan Sleman. Kabupaten ini berbatasan dengan Provinsi Jawa Tengah di utara dan timur, Kabupaten Gunung Kidul, Kabupaten Bantul, dan Kota Yogyakarta di selatan, serta Kabupaten Kulon Progo di barat. Sleman dikenal sebagai asal buah salak pondoh. Sleman mempunyai motto yaitu sembada (Sehat, Elok, Makmur dan merata, Bersih dan berbudaya, Aman dan adil, Damai dan dinamis, Agamis). Kabupaten dengan image pendidikan dan wisata merupakan bagian dari Kabupaten Sleman dengan luas wilayah $574,82 \mathrm{~km}^{2}$, terdapat 17 kecamatan, 86 kelurahan dan 1.212 padukuhan (Wikipedia, 2010).

Sleman merupakan kabupaten dengan pengembangan wilayah yang cukup cepat. Permintaan akan pemanfaatan lahan yang terus tumbuh dan bersifat akseleratif untuk untuk pembangunan berbagai fasilitas termasuk kemajuan teknologi, industri dan transportasi. Selain sering mengubah konfigurasi alami lahan atau bentang alam juga menyita lahan-lahan tersebut dan berbagai bentukan ruang terbuka lainnya. Kedua hal ini umumnya merugikan keberadaan 
ruang terbuka hijau (RTH) yang sering dianggap sebagai lahan cadangan dan tidak ekonomis. Di lain pihak, kemajuan alat dan pertambahaan jalur transportasi dan sistem utilitas sebagai bagian dari peningkatan kesejahteraan masyarakat juga telah menambah jumlah bahan pencemar dan telah menimbulkan berbagai ketidaknyamanan di lingkungan perkotaan. Karena ruang tidak dapat bertambah, maka yang terjadi adalah perubahan penggunaan lahan, yang cenderung menurunkan proporsi lahan-lahan yang sebelumnya merupakan RTH khususnya di Kecamatan Sleman, Kabupaten Sleman.

Kecamatan Sleman merupakan Ibukota dari Kabupaten Sleman. Jarak kantor Kecamatan ke Pusat Pemerintahan (Ibukota) Kabupaten Sleman adalah $4 \mathrm{Km}$. Lokasi ibu kota kecamatan Sleman berada di 7,684100 LS dan 110,340440 BT. Kecamatan Sleman mempunyai luas wilayah 3.132 ha dengan jumlah penduduk 63.478 jiwa (Wikipedia, 2010). Kecamatan Sleman terbagi menjadi 5 desa yaitu Desa Caturharjo, Desa Pendowoharjo, Desa Tridadi, Desa Triharjo, Desa Trimulyo. Kecamatan Sleman mempunyai bentuk wilayah yang datar dan berombak. Berada pada ketinggian 243 meter dpl (Website Kabupaten Sleman, 2010)

Saat ini banyak sekali perubahan pola lingkungan yang disebabkan oleh berkembangnya kawasan RTH di Kecamatan Sleman menjadi kawasan ruang terbangun. Hal ini menyebabkan beberapa perubahan alam terutama pada tingkat suhu, cuaca dan tingkat polusi udara. Untuk mengatasi kondisi lingkungan kota seperti ini sangat diperlukan RTH sebagai suatu teknik bentukan biofilter yang relatif lebih murah, aman, sehat, dan nyaman. Berdasarkan permasalahan tersebut perlu dilakukan adanya evaluasi terhadap ketersediaan RTH guna mengembalikan fungsi utama RTH di Kecamatan Sleman.

\section{BAHAN DAN METODE}

Penelitian ini telah dilaksanakan di Kecamatan Sleman Kabupaten Sleman. Penelitian dilakukan menggunakan metode survei, yang teknis pelaksanaannya dilakukan dengan observasi, kuesioner dan pengumpulan data sekunder. Observasi dilakukan untuk mendapatkan informasi tentang kondisi eksisting wilayah, yang akan menggambarkan keadaan awal kawasan tersebut. Pemilihan lokasi observasi dilakukan secara purposive yaitu pemilihan lokasi berdasarkan tujuan tertentu yang didasarkan pada jalan-jalan utama, kepadatan lalu-lintas, pemukiman padat penduduk, area perdagangan dan lain sebagainya yang berada di Kecamatan Sleman.

Penyebaran kuesioner dilakukan dengan memberikan sejumlah daftar pertanyaan kepada responden dengan asumsi dapat mewakili sifat populasi secara keseluruhan. Roscoe dalam Sugiyono (2009), memberikan saran-saran tentang ukuran sampel untuk penelitian diantaranya adalah (1) Ukuran sampel yang layak dalam penelitian adalah antara 30 sampai dengan 500 . (2) Bila sampel dibagi dalam kategori (misalnya: pria-wanita, pegawai negeri-swasta, pelajar, pedagang dan lain-lain) maka jumlah anggota sampel setiap kategori minimal 30.

Kuesioner yang disebar sebanyak 100, yang terbagi menjadi 40 sampel pelajar, 30 sampel PNS, dan 30 sampel pedagang. Untuk pemilihan sampel responden dan lokasi responden juga dilaksanakan dengan purposive, yaitu pemilihan responden didasarkan pada wilayah-wilayah strategis yang ada di Kecamatan Sleman seperti instansi pemerintahan, sekolah, alun-alun dan lain sebagainya. Responden yang dipilih adalah masyarakat yang berada di sekitar Kecamatan Sleman yang sengaja dipilih sesuai dengan tujuan penelitian. Penyebaran kuesioner dilakukan dengan memberikan sejumlah daftar pertanyaan 
kepada responden dengan asumsi dapat mewakili sifat populasi secara keseluruhan. Hal ini diperlukan untuk mengetahui tingkat dukungan pengguna terhadap perencanaan kawasan yang akan dibuat, sehingga dapat meredam gejolak sosial yang akan terjadi, sebab penelitian ini akan bersinggungan dengan kepentingan banyak pengguna.

Hasil observasi dan penyebaran kusioner perlu didukung oleh data-data sekunder seperti mengenai batas-batas wilayah, luas, ketinggian tempat, topografi, iklim, kondisi sosial masyarakat yang dicatat dalam angka serta peta, sehingga memperkuat gambaran sosial masyarakat dan kondisi geografis wilayah. Data sekunder yang diperlukan diperoleh dari instansi terkait, diantaranya Dinas Pekerjaan Umum dan Perumahan, BAPPEDA, BPS dan Kantor Kecamatan setempat.

Data yang telah terkumpul kemudian dianalisis secara deskriptif. Analisis deskriptif digunakan untuk memberikan gambaran, penjelasan dan uraian hubungan antara satu faktor dengan faktor lain berdasarkan fakta, data dan informasi kemudian dibuat dalam bentuk tabel atau gambar. Dilanjutkan membuat contoh model penataan RTH untuk meningkatkan nilai fungsional dan estetika di Kecamatan Sleman.

\section{HASIL DAN PEMBAHASAN}

Di Kecamatan Sleman terdapat beberapa taman kota antara lain taman yang bersifat aktif atau lebih bersifat pasif. Taman yang bersifat aktif yaitu taman yang memiliki fungsi sebagai tempat bermain atau digunakan untuk beraktivitas yang memanfaatkan elemen-elemen pendukung seperti ayunan, jogging track, kursi dan lain sebagainya. Salah satu contoh taman aktif yang ada adalah Taman Denggung yang biasa digunakan oleh masyarakat sekitar untuk berolahraga atau menikmati suasana vista yang ada. Sedangkan taman yang bersifat pasif seperti Taman Pringgodiningrat atau Traffic Island yang lebih berfungsi sebagai elemen estetis, sehingga untuk taman pasif hanya terdiri dari tanaman semak, tanaman pendek dan juga elemen patung di dalamnya.

Kecamatan Sleman merupakan kecamatan yang bersifat asri dan dinamis memiliki Taman Kota sekaligus sebagai Hutan Kota yaitu Hutan Denggung yang tersusun dari vegetasi yang ada sangat bervariasi dan disusun secara rapi dan berselang seling. Taman Denggung dapat dimanfaatkan sebagai Taman Kota karena di dalamnya terdapat elemen-elemen pendukung seperti tempat duduk, area bermain, patung dan lain sebagainya yang dapat dimanfaatkan oleh pengguna. Pada area Taman Denggung terdapat berbagai vegetasi pohon besar yang bergerombol dan tertata, sebagian besar adalah glodokan, kepel dan angsana dengan jumlah total vegetasi didalamnya 291 batang dan 69 spesies tanaman.

RTH yang berkualitas cukup baik antara lain berupa jalur hijau (path) pada median dan sepadan jalan utama di Kecamatan Sleman, hal seperti ini nampak pada Jalan KRT. Pringgodiningrat dan Jalan Magelang dengan vegetasi peneduh pada sepadan jalan dan vegetasi pengarah pada median jalan. Tanaman tepi jalan atau yang populer disebut dengan koridor hijau (green corridor) merupakan salah satu tipe RTH yang terdapat di kawasan Kecamatan Sleman dan kondisinya cukup bervariasi yang memliki nilai keindahan yang nampak sekali dinikmati oleh pengguna. Beberapa variasi vegetasi yaitu vegetasi pengarah dan vegetasi peneduh seperti yang dapat dilihat pada jalan KRT Pringgodiningrat dan Jalan Magelang.

Kecamatan Sleman yang memiliki jumlah penduduk sebesar 63.478 jiwa terdiri dari lakilaki berjumlah 30.933 jiwa dan perempuan 
32.545 jiwa. Jumlah penduduk di atas berwarga negara Indonesia Sedangkan kepadatan penduduk Kecamatan Sleman pada tahun 2009 adalah 2.026,75 jiwa per $\mathrm{km}^{2}$. Pendidikan merupakan faktor yang sangat penting karena pendidikan merupakan aset dan penerus generasi bangsa. Pada tahun ajaran 2008/2009 Kecamatan Sleman memiliki fasilitas sekolah sebanyak 15 unit, jumlah siswa sebayak 5.355 serta jumlah guru sebanyak 503.

Hasil dari pengamatan data di lapangan, presepsi masyarakat sekitar kecamatan Sleman memahamai apa yang dimaksud dengan RTH yaitu 57\%. Namun demikian banyak juga yang tidak mengetahui apa yang di maksud RTH, hal ini dapat diketahui dari angka persentase masyarakat yang tidak mengetahui yaitu $43 \%$ hanya berselisih sedikit dengan masyarakat yang mengetahui. Mayoritas mengetahui apa yang dimaksud RTH setelah mengisi pertanyaan berikutnya. Hal ini dibuktikan dengan pengertian mereka bahwa RTH adalah Kumpulan pohon yang bergerombol dalam areal tertentu (51\%) dan Kumpulan pohon yang menyebar dan atau gerombolan kecil (43\%) atau mereka lebih menilai RTH sebagai kawasan hutan.

Kecamatan Sleman masih membutuhkan elemen tanaman untuk kenyaman (100\%) karena, mereka merasakan kondisi saat ini yang panas (42\%) dan berdebu (37\%). Terutama pada siang hari kepadatan lalu lintas dan polusi udara yang menyebar membuat kondisi menjadi panas dan berdebu. RTH mempunyai manfaat mempertahankan kualitas lingkungan (91\%) dan keindahan lingkungan (78\%).

Persepsi masyarakat yang setuju akan pentingnya keberadaan taman kota di mana angka setuju adalah 100\% . Menurut persepsi masyarakat ada tiga macam jenis taman yang diinginkan yaitu taman rekreasi (65\%), taman bermain
(51\%) dan taman dengan berbagai tanaman hias (57\%). Hal ini dirasakan masyarakat akan mempertahankan kualitas lingkungan,sebagai pembelajaran dan nilai estetis yang akan dimunculkan.

Masyarakat yang perlu adanya hutan kota (98\%) dan memiliki peran yang sangat penting, 74\% masyarakat menyatakan bahwa hutan kota memiliki peran untuk pelestari lingkungan yaitu sebagai paru-paru kota, penurun suhu dan sebagai ruang hidup satwa. Selain itu 61\% masyarakat menilai peran hutan kota untuk mengurangi polusi dan kebisingan, dan $26 \%$ responden menyatakan hutan kota sebagai tempat rekreasi untuk keluarga.

Kondisi jalan di Kecamatan Sleman 72\% masyarakat menyatakan kondisinya nyaman tetapi hanya di beberapa ruas jalan saja. Sedangkan 7\% masyarakat menyatakan kondisi ruas jalan di Kecamatan Sleman tidak nyaman. hal ini di karenakan di beberapa jalan kabupaten yang sudah banyak ditambal sehingga pengguna tidak merasa nyaman. Jumlah pohon peneduh di tepi jalan $72 \%$ masyarakat menyatakan kurang banyak. 92\% masyrakat berpendapat bahwa salah satu fungsi tanaman tepi jalan adalah sebagai peneduh dan $27 \%$ responden menyatakan bahwa fungsi tanaman untuk hiasan atau lebih bertujuan sebagai nilai keindahan. Untuk memperindah kawasan Kecamatan Sleman responden setuju $100 \%$ bahwa tanaman akan memperindah kawasan tersebut.

Di dalam rencana tata ruang wilayah (RTRW) Kota Sleman tahun 1999 sampai 2009, ada beberapa pengembangan unsur-unsur utama Kota Sleman yang diarahkan pada penciptaan lingkungan kota yang mampu meningkatkan daya dukung setempat dalam rangka pengembangan. Beberapa unsur penggunaan ruang atau lahan seperti pemukiman, perdagangan, perkantoran, pendidikan, industry, sawah, kesehatan dan 
ruang hijau atau rekreasi. Rencana pemanfaatan ruang di Kecamatan Sleman lebih tertuju pada pengembangan lingkungan perumahan atau pemukiman dan pengembangan lingkungan pusat perdagangan.

Penggunaan kawasan pemukiman di Kecamatan Sleman mengalami peningkatan, dari data RTRW tahun 1999 tercatat bahwa luas lahan yang baru dimanfaatkan untuk area pemukiman terbangun adalah sebesar 33,13\%. Dibandingkan dengan data penggunaan lahan terbangun pada tahun 2009 yaitu 34,51\% atau meningkat 1,38\% dari sepuluh tahun sebelumnya. Melihat data yang ada pengembangan kawasan pemukiman sangat mengancam keberadaan RTH terutama di kawasan pusat kota yang menjadikan daerah hijau sebagai paru- paru kota. Penduduk banyak yang terpusat di pusat kota dan menjadikan ruang sebagai lingkungan pemukiman atau area perdagangan, khususnya di dekat kantor kecamatan. Kondisi tersebut sangat beralasan, karena di tempat tersebut memilki daya jangkau atau akses yang cukup tinggi untuk menuju maupun dituju dari pusat- pusat kegiatan di luar wilayah Kecamatan Sleman.

Menurut Undang-Undang No. 26 tahun 2007, proporsi RTH di perkotaan paling sedikit $30 \%$ dari luas wilayahnya dan untuk RTH publik adalah 20\%. Kecamatan Sleman yang memiliki luas $3.132 \mathrm{Ha}$ dan memiliki luas wilayah terbangun sebesar $34,51 \%$ yakni $1.117,75 \mathrm{Ha}$ dan wilayah tidak terbangun sebesar $67,56 \%$ sebesar 2014,25 Ha.

Melihat keterangan di atas, maka luas ideal RTH publik yang dibutuhkan adalah 626,4 Ha. Untuk mengetahui kekurangan luas RTH yang dibutuhkan maka diperlukan data luas jenis pemanfaatan RTH non terbangun seperti taman kota, jalan, lapangan, kuburan dan sawah.

Pada Tabel 1 terlihat bahwa terlihat bahwa kebutuhan akan RTH publik sangat kurang dari kebutuhan ideal. Kebutuhan RTH publik di Kecamatan Sleman kurang dari 626,4 Ha atau 20\% dari wilayah tersebut. Dari jenis luasan RTH publik yang ada seperti taman kota, hutan kota, jalan, lapangan, dan kuburan dapat dilihat bahwa luas RTH publik yang ada 35,84 atau 1,14\% dari kebutuhan ideal yaitu 626,4 Ha.

Tabel 1. Jenis dan luas ruang terbuka di Kecamatan Sleman

\begin{tabular}{llc}
\hline No. & Jenis Ruang Terbuka & Luas \\
\hline 1. & Taman kota \& Hutan Kota & $0,9788 \mathrm{Ha}$ \\
2. & Total jalan & $10,5 \mathrm{Ha}$ \\
3. & Lapangan & $10,15 \mathrm{Ha}$ \\
4. & Kuburan & $14,221 \mathrm{Ha}$ \\
\hline & Jumlah & $35,84 \mathrm{Ha}$ \\
\hline
\end{tabular}

Kebutuhan RTH publik dapat terpenuhi dengan solusi yaitu memanfaatkan ruang-ruang yang kosong dengan penambahan ruang hijau seperti taman kota dan hutan kota. Selaian itu, penambahan taman minimalis pada ruang terbangun atau ruang terbuka non hijau yang memilki keterbatasan lahan dapat dilakukan dengan membuat taman minimalis pada area sekitar bangunan yang penempatan elemen pendukung seperti tanaman dan hard material dapat menggunakan median tambahan.

Pada kondisi yang seperti ini, maka dibutuhkan juga peran serta masyarakat untuk menjaga kualitas RTH yang ada dengan mengutamakan keseimbangan kelestarian lingkungan untuk jangka panjang. Dalam pelaksanaannya, pembangunan dan pengelolaan RTH juga mengikutsertakan masyarakat untuk meningkatkan apresiasi dan kepedulian mereka terhadap kualitas lingkungan alami sekitarnya yang cenderung menurun.

Perencanaan RTH di Kecamatan Sleman ini bertujuan untuk membuat model penataan RTH 
guna meningkatkan nilai fungsional, estetika dan penambah ruang hijau yang ada. Elemen vegetasi atau tanaman merupakan unsur yang dominan dalam RTH. Vegetasi dapat ditata sedemikian rupa agar mampu berfungsi sebagai pembentuk ruang, pengendalian suhu udara, memperbaiki kondisi tanah dan sebagainya.

Pada area taman kota yang perlu dilakukan penataan pertigaan Pringgodiningrat atau Pertigaan Denggung. Perencanaan yang dilakukan untuk menembah kesejukan dan nilai estetik perlu penambahan berupa air mancur. Hal ini di karenakan dengan penambahan air mancur pada bagian tengan taman akan dapat memecahkan kepenatan dan kondisi panas pada perempatan jalan ini. Air mancur tersebut juga bisa berfungsi sebagai filter udara. Semua air mancur menghasilkan partikel ion-ion negatif yang tercipta dari golakan air-air yang jatuh. Setiap partikel ion negatif tersebut dapat mengikat debu serta zat kimia yang ada di udara sehingga air mancur tersebut dapat dikatakan mem-filter udara.

Penempatan tanaman sancivera dengan jarak tanam yang rapat akan berfungsi untuk menyerap polusi udara karena tanaman ini memiliki ketahanan terhadap cuaca yang ekstrim. Penempatan tanaman pohon seperti beringin, ketapang dan glodokan bulat pada tepi jalan dengan tajuk melebar dan berdaun padat dapat berfungsi untuk memberi keteduhan, dalam arti mengurangi sengatan atau penahan sinar matahari dan untuk memberikan kenyamanan bagi pengguna di sekitarnya. Model perencanaan taman kota Traffic Island tersaji pada Gambar 1.

Penambahan taman kota dapat dilakukan dengan melihat ruang kosong yang ada misalnya di jalur pertigaan. Pertigaan kelurahan Triharjo memerlukan penataan ulang taman, Pertigaan Triharjo merupakan penghubung tiga arah tujuan yaitu jalan magelang, kelurahan Triharjo, padukuhan dan beberapa sekolah di sekitarnya. Perencanaan yang dilakukan yaitu menata ulang taman dengan memperhatikan syarat-syarat yang memiliki nilai fungsional dan estetika. Pada tengah taman diisi dengan tanaman ketapang sebagai tanaman peneduh dan pada area sekitarnya ditempatkan bangku untuk bersantai menikmati suasana sekitar. Penempatan rumput manila sebagai tanaman penutup, bunga sepatu dan lampu taman adalah untuk menambah nilai estetika pemandangan dan fungsionalnya.

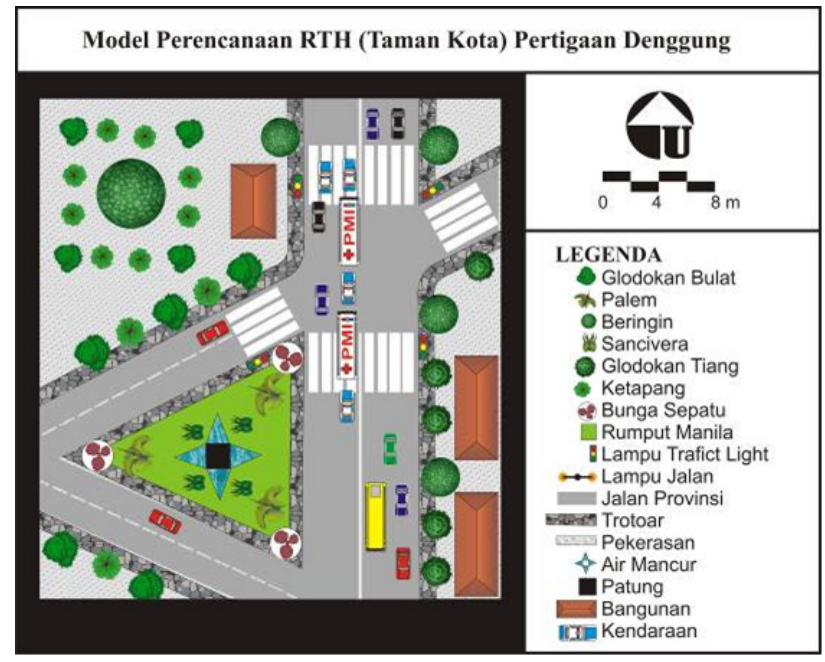

Gambar 1. Contoh Model Perencanaan RTH (Taman Kota) Pertigaan Denggung

Tanaman tetehan dan glodokan bulat berfungsi untuk penyerap polusi dan pemecah kebisingan, karena posisi taman ini yang berdampingan dengan jalan provinsi yang cukup padat pengendara. Selain itu, penambahan hard material akan menambah kesan estetiknya, seperti jalan setapak dan bangku untuk beraktivitas. Model Perencanaan RTH (Taman Kota) di pertigaan Triharjo tersaji pada Gambar 2.

Hutan kota merupakan bentuk persekutuan vegetasi pohon yang mampu menciptakan iklim mikro dan lokasinya di perkotaan atau dekat kota. Di Kecamatan Sleman yaitu di pertigaan Jamban area ini terdapat elemen eksisting kolam 
pemancingan dan tanaman-tanaman berkayu seperti glodokan, beringin, mangga, jarak, ketapang, sukun, bambu kuning dan lain sebagainya yang tertata. Namun, tempat ini sudah lama terbengkalai atau tidak terawat sehingga menimbulkan kesan kotor dan kumuh. Oleh karena itu taman asri ini diharapkan dikelola menjadi hotan kota yang memang elemen eksistingnya sudah mendukung.

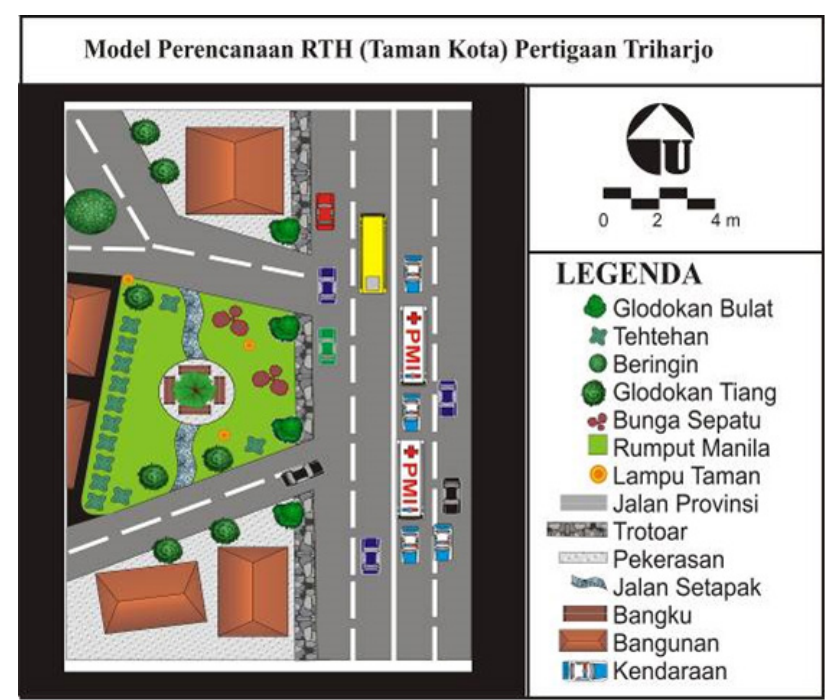

Gambar 2. Contoh Model Perencanaan RTH (Taman Kota) di Pertigaan Triharjo

Model hutan kota yang direncanakan adalah hutan kota dengan komposisi vegetasi dengan strata yang bervariasi. Diharapkan dengan bentuk tajuk yang bervariasi dengan penempatan atau pengaturan tata ruang yang sesuai akan memberi kesan keindahan tersendiri. Selain itu penambahan beberapa elemen seperti lampu, gazebo dan jalan kecil di dalamnya diharapkan hutan ini bersifat aktif.

Pemilihan tanaman untuk dijadikan hutan kota yaitu meliputi beringin, akasia, glodokan bulat, jarak dan nangka. Penempatan tanaman pohon seperti beringin dan akasia yaitu bertujuan untuk menghasilkan $\mathrm{O}_{2}$ dan penyerap $\mathrm{CO}_{2}$, memiliki umur yang panajang dan tidak memer- lukan perawatan yang intensif. Penambahan hard material seperti jalan setapak gazebo dan kolam pemancingan akan menimbulkan aktivitas yang ada didalamnya dan dapat digunakan sebagai tempat untuk beristirahat menikmati suasana sekitar di gazebo, atau masyarakat dapat melakukan aktivitas pemancingan di jalan setapak dengan adanya tanaman jarak sebagai peneduh sehingga aktivitas memancing tidak terganggu dengan cuaca yang panas. Model Perencanaan RTH (Hutan Kota) Pertigaan Jamban tersaji pada gambar 3.

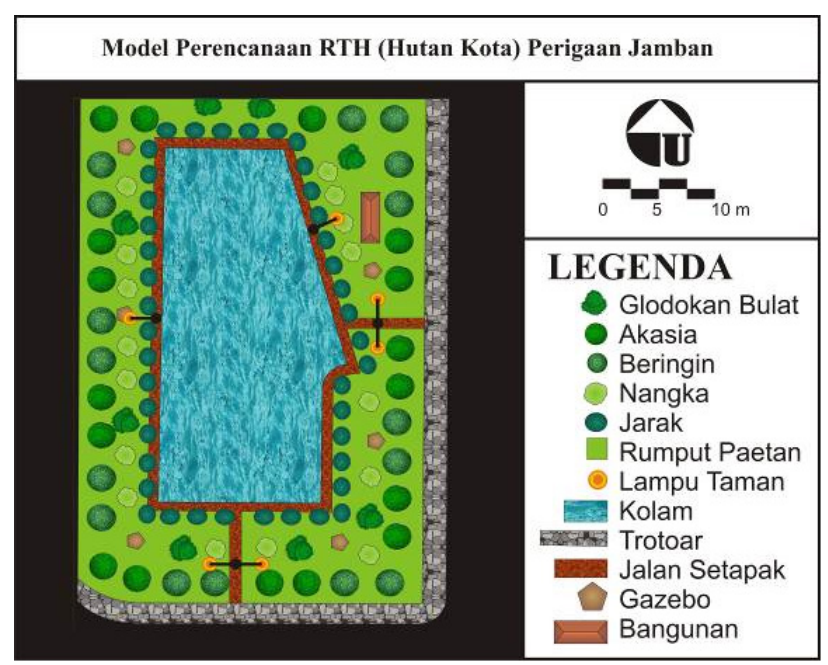

Gambar 3. Model Perencanaan RTH (Hutan Kota) Pertigaan Jamban

Pada jalan-jalan di Kecamatan Sleman banyak bangunan dan tanaman yang penempatannya kurang efektif. Melihat kondisi tersebut bisa diterapkan penambahan tanaman tepi jalan, Penambahan pot pada median jalan juga dapat dimanfaatkan sebagai pembentuk RTH yang bermanfaat juga sebagai pembatas, pengarah dan estetika. Jalan Magelang merupakan salah satu jalan utama di Kecamatan Sleman, jalan tersebut terletak di pusat kota dengan jalur satu arah yang menghubungkan Yogyakarta dengan magelang dan semarang. Aktivitas jasa dan perdagangan banyak terdapat di sepanjang jalan ini, selain itu 
terdapat juga pusat kantor dan pusat bisnis di sekitarnya.

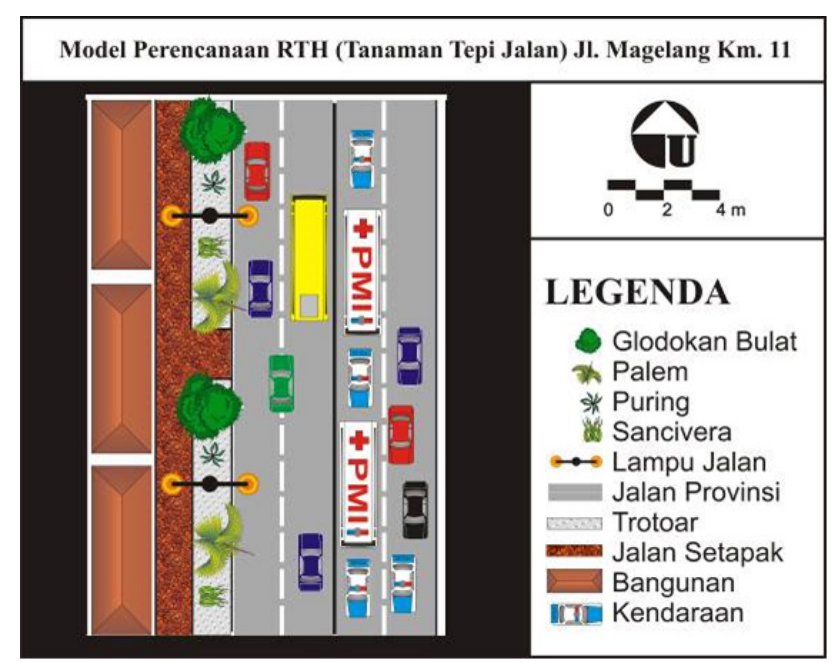

Gambar 4. Model Perencanaan RTH (Tanaman Tepi Jalan) Jl. Magelang Km. 11

Model penataan pada median jalan ini yaitu dengan penamabahan Tiang lampu yang berdiri di tengah median yang diletakkan satu garis lurus dengan jalan supaya tidak mengganggu pengguna jalan. Hal ini bertujuan agar menambah keindahan di malam hari. Jenis tanaman yang ada hanya palem dan tetehan yang terdapat di median jalan. Kondisi sepanjang jalan masih cukup panas untuk dilewati sehingga perlu ada penambahan beberapa tanaman peneduh dan tanaman hias. Tanaman peneduh yang ada hanya palem yang terdapat di median timur jalan, maka perlu penambahan tanaman peneduh di sebelah barat samping pedestrian sehingga akan terlihat seimbang. Kondisi Eksisting Jalan Magelang km.11 Sebelum Perencanaan dan model perencanaan RTH (Tanaman Tepi Jalan) Jl.Magelang Km.11 tersaji pada Gambar 4.

\section{SIMPULAN DAN SARAN}

Kesimpulan dari penelitian ini adalah (1) Kecamatan Sleman memiliki ruang terbuka hijau publik yang kurang yaitu 35,84 $\mathrm{Ha}$ atau 1,14\% dari luas ideal 624,4 Ha Mengacu pada UU RI No. 26 tahun 2007. (2) Model penataan sebagai acuan peningkatan nilai estetik, fungsional dan menambah RTH yang ada di Kecamatan Sleman dapat dilakukan dengan penambahan taman kota, hutan kota, tanaman tepi jalan dan penambahan air mancur yang memiliki nilai fungsional dan estetika.

Dari hasil penelitian disarankan bahwa: (1) Sudah selayaknya Pemerintah Daerah Sleman memberi perhatian khusus pada keberadaan RTH yang masih kurang dari kebutuhan ideal. (2) Perlu kejelasan manajemen anggaran, pengadaan dan pemeliharaan untuk kebutuhan RTH dari Pemerintah Daerah Sleman

\section{DAFTAR PUSTAKA}

Aini, L N. 2008. Diktat Desain Lanskap. Fakultas Pertanian UMY.

Kabupaten Sleman. 2007. Kabupaten Sleman Dalam Angka. Badan Pusat Statistik Kabupaten Sleman. 2010. Ruang Terbuka Hijau. Dalam http: // id.wikipedia.org/ wiki / Kabupaten_Sleman akses 16 maret 2010.

Pemerintah Kabupaten Sleman. 2010. Lokasi dan Luas Taman Kota Di Kabupaten Sleman. Dinas Pekerjaan Umum dan Perumahan.

Pemerintah Kabupaten Daerah Tingkat II Sleman. 1999. Rencana Detail Tata Ruang Kota Sleman Tahun 1999 - 2009 (Rencana). Badan Perencanaan Pembangunan Daerah Kabupaten Dati II Sleman.

Pemerintah Kecamatan Sleman. 2009. Tabulasi Data Profil Desa Semester II. Kecamatan Sleman, Kabupaten Sleman.

Sugiyono. 2009. Metode Penelitian Kuantitatif, Kualitatif dan R\&D. Alfabeta. Bandung.

Wikipedia.2010. Dalam.http://id.wikipedia.org/wiki/Statistika_ deskriptif. Akses 14 april 2010

Undang-Undang Republik Indonesia Nomor 26 Tahun 2007 Tentang Penataan Ruang. Di akses dari http://www.penataanruang.net/taru/nspm/ UU_No26_2007_Tentang_Penataan_Ruang.pdf pada tanggal 5 Desember 2009. 